\title{
The languages we use
}

\author{
RICHARD S. LEHMAN \\ Franklin \& Marshall College, Lancaster, Pennsylvania
}

\begin{abstract}
Members of the Society for Computers in Psychology responded to a survey concerning their programming practices and language use. The results reveal current hardware and software use; relationships among computer science training, task, and language choice and usage; and areas in which attention to some structured programming principles might improve the code that psychologists write.
\end{abstract}

Members of the Society for Computers in Psychology (SCP) responded to a survey concerning their programming practices and language use. Most of the questions were software oriented, but hardware use was surveyed as well. Particular attention was directed toward the use of various rules and procedures of "structured programming" and the logic of language choice. Questionnaires were sent to over 300 SCP members. The cover letter and questionnaire invited recipients to make copies of the survey for students, assistants, or other non-SCP members. The questionnaire was accompanied by a postagepaid return envelope.

\section{RESULTS OF THE SURVEY}

A total of 137 individuals returned surveys, with $65 \%$ supplying their names as a request for a copy of the results. Two respondents were excluded from the analysis because they indicated that they no longer write code. As would be expected, the great majority of respondents were faculty members at colleges and universities (see Table 1). Most respondents listed themselves as self-taught programmers, but a substantial minority had had collegelevel computer science training.

The cited computers are listed in Table 2. A mean of $3.0(S D=1.0)$ different computers were listed by each respondent. The first languages learned are listed in Table 3. BASIC and FORTRAN were by far the most common first languages, but the various assemblers made a substantial showing. Note the low position of Pascal, the language of choice in computer science instruction; only 2 individuals said they had learned it first. The firstlanguage data show an early involvement in computing by a number of psychologists. Several people reported that their first language was absolute machine language (not assembler) or Autocoder for early IBM machines, which establishes their computer history as beginning in the early 1960s. FOCAL and MAD date to roughly the same era, and 1 respondent dated his/her introduction to computing to the Whirlwind at MIT (mid-1950s).

The author's address is Franklin \& Marshall College, P.O. Box 3003, Lancaster, PA 17604.
Table 1

Information About Respondents $(N=135)$

\begin{tabular}{|c|c|c|}
\hline & Number & Percent \\
\hline \multicolumn{3}{|l|}{ Occupation } \\
\hline Faculty member & 96 & 71.1 \\
\hline Programmer & 1 & .7 \\
\hline Student & 8 & 5.9 \\
\hline Researcher & 19 & 14.1 \\
\hline Technician & 2 & 1.5 \\
\hline Other & 9 & 6.6 \\
\hline \multicolumn{3}{|l|}{ Place of employment } \\
\hline Four-year college & 25 & 18.5 \\
\hline University & 89 & 65.9 \\
\hline Industry & 6 & 4.9 \\
\hline Research institution & 6 & 4.4 \\
\hline Other & 9 & 6.7 \\
\hline \multicolumn{3}{|c|}{ How did you learn programming?* } \\
\hline Self-taught & 121 & 89.6 \\
\hline High school course & 8 & 5.9 \\
\hline College computer science course & 63 & 46.7 \\
\hline "Computers in psychology" college course & 7 & 5.2 \\
\hline Industrial training & 13 & 9.6 \\
\hline Other & 9 & 6.7 \\
\hline
\end{tabular}

*More than one answer allowed.

Table 4 summarizes the respondent's division of their professional activities in terms of percentage of time spent in each.

\section{Structured Programming}

One question requested attitude ratings on a set of "rules" for structured programming, with separate ratings for whether the respondents agreed with a rule and whether they actually followed it in their own programming. The rating scale was from 1 (do not believe in or never do) to 5 (believe in or always do). Table 5 summarizes the mean ratings for all respondents. In every case but one, the respondents admitted to not practicing their beliefs in their coding. On the whole, though, they reported following many of the guidelines; only two of the mean ratings fall below the midpoint on the scale. The self-perception, then, seems to be that the respondents write reasonably good, structured code. (The degree to which the respondents claim to actually use these "good programming practices" may come as a surprise to the editors and reviewers who see some of their code.) 
Table 2

Computers Used

\begin{tabular}{lc}
\hline \multicolumn{1}{c}{ Computer } & $\begin{array}{c}\text { Number } \\
\text { reporting use* }\end{array}$ \\
\hline IBM PC & 73 \\
Kaypro & 2 \\
Other IBM PC clone & 29 \\
Apple II series (or clone) & 65 \\
Apple Macintosh & 37 \\
Tandy (TRS) & 7 \\
Commodore & 9 \\
Other microcomputer & 32 \\
SUN workstation & 13 \\
PDP 8 or 11 & 16 \\
Other minicomputer & 14 \\
DEC VAX mainframe & 56 \\
IBM mainframe & 37 \\
CDC mainframe & 9 \\
Other mainframe & 9 \\
\hline
\end{tabular}

Note $-N=135 . \quad$ *Multiple responses permitted.

Table 3

First Language Learned

\begin{tabular}{lrc}
\hline & Number & Percent \\
\hline FORTRAN (all versions) & 62 & 47.0 \\
BASIC (all versions) & 28 & 21.2 \\
Miscellaneous assembly & 10 & 7.6 \\
PDP 5/8/11 assembly & 5 & 3.8 \\
IBM 650 machine code & 4 & 3.0 \\
IBM 1401/7080 Autocoder & 3 & 2.3 \\
IBM 1620 machine code & 3 & 2.3 \\
Other machine code & 3 & 2.3 \\
ALGOL & 2 & 1.5 \\
APL & 2 & 1.5 \\
FOCAL & 2 & 1.5 \\
MAD & 2 & 1.5 \\
Pascal & 2 & 1.5 \\
LISP & 1 & .8 \\
PL/1 & 1 & .8 \\
SKED & 1 & .8 \\
Whirlwind Assembler & 1 & .8 \\
Total & 132 & \\
\hline
\end{tabular}

Note $-N=132$.

Table 4 Division of Respondents' Time

\begin{tabular}{lrr} 
& \multicolumn{2}{c}{ Percent of time } \\
\cline { 2 - 3 } \multicolumn{1}{c}{ Activity } & \multicolumn{1}{c}{$M$} & $S D$ \\
\hline Teaching & 27.9 & 24.8 \\
Writing & 16.2 & 15.1 \\
Research (nonwriting) & 21.8 & 15.2 \\
Program debugging & 6.3 & 8.1 \\
Program designing & 6.0 & 6.8 \\
Program coding & 6.1 & 8.2 \\
Programming (not specified) & 2.8 & 10.0 \\
Other (often administrative) & 11.7 & 20.4 \\
\hline
\end{tabular}

To see whether formal training in computer science had an effect on respondents' following the rules of structured programming, data were analyzed separately for those people who had learned to program in a computer science course (or had at least taken one) and those who had not. The within-rule differences shown in Table 5 were evident in both groups of respondents. There was a single between-groups difference: computer science-trained respondents reported that they used global variables significantly more than did those without such training.

A number of respondents noted that some of the questions were confounded with the languages themselves, and it is certainly true that FORTRAN and BASIC programmers have more difficulty in using DO-WHILE constructions and avoiding GOTO statements than do programmers in Pascal or C. In an effort to look at some of the differences in programming practices by practitioners of different languages, respondents were grouped into five categories on the basis of the language (BASIC, FORTRAN, Pascal, C, or LISP) in which they wrote the majority of their code. (The remaining languages were used by too few programmers to analyze.) These data are too voluminous and uninteresting to present in tabular fashion, but several trends can be summarized.

FORTRAN and BASIC programmers seemed to be less concerned with the appearance of code; they reported that they were less likely to limit the length of their routines and tended not to value or use indenting and other techniques to make their listings readable. On the other hand, FORTRAN and BASIC programmers were much more likely to actually write the documentation for their programs. (But BASIC, FORTRAN, Pascal, and C programmers valued documentation equally, with a mean rating of 4.4, versus a mean of 2.8 for LISP writers.) LISP programmers differed from other programmers in their opinions and use of variable typing (that, however, is a language confound), and reported that they wrote annotations significantly less than did all other programmers.

The only other between-groups difference in structured programming attitudes and use was a language-determined one: FORTRAN and BASIC programmers did not use DO-WHILE and REPEAT-UNTIL constructions. No other programmer-group differences were significant.

Despite the confounding of some questions with languages, we may conclude that structured programming seems not to have had a major impact on the programming practices of psychologists. Although many rate some of the principles of the discipline as valuable, most fail to follow them. Even people with formal training in computer science, who should be the most well indoctrinated in its rules and practices, do not follow its dictates significantly more than do those whose training does not include computer science.

\section{Languages Used}

Table 6 shows language use. The first column presents the languages used as a percentage of all reported code written. For example, $C$ represents a mean of $9.3 \%$ of all code written by the 135 individuals summarized, a relatively small percentage. However, the 24 respondents who reported using $\mathrm{C}$ reported writing an average of $44.2 \%$ of their code in the language. Likewise, although only 2 respondents reported using Modula, they reported that $55 \%$ of their total output was in Modula.

The great bulk of coding was in BASIC and Pascal, with C, FORTRAN, and LISP representing somewhat smaller percentages. The less frequently used languages, however, 
Table 5

Attitude Toward and Use of the Rules of Structured Programming

\begin{tabular}{|c|c|c|}
\hline Rule & "Believe in" & "Actually do" \\
\hline $\begin{array}{l}\text { Limit program modules to one page } \\
\text { of code each }\end{array}$ & 3.1 & $2.9 *$ \\
\hline Avoid GOTO statements & 3.3 & $3.0^{*}$ \\
\hline $\begin{array}{l}\text { Never transfer into/out of the } \\
\text { middle of a loop }\end{array}$ & 4.1 & $3.8^{*}$ \\
\hline $\begin{array}{l}\text { Construct each module with a single } \\
\text { entry and exit }\end{array}$ & 3.7 & 3.6 \\
\hline $\begin{array}{l}\text { Use DO-WHILE and REPEAT- } \\
\text { UNTIL constructions }\end{array}$ & 3.8 & $3.3^{*}$ \\
\hline $\begin{array}{l}\text { Use descriptive variable and } \\
\text { procedure names }\end{array}$ & 4.7 & $4.3^{*}$ \\
\hline Give careful thought to variable types & 4.2 & $3.9^{*}$ \\
\hline $\begin{array}{l}\text { Write informative comments in the } \\
\text { code }\end{array}$ & 4.5 & $3.2^{*}$ \\
\hline Write the documentation & 4.3 & $3.1^{*}$ \\
\hline $\begin{array}{l}\text { Plan programs using top-down } \\
\text { design }\end{array}$ & 4.0 & $3.2^{*}$ \\
\hline Avoid "global" variables & 3.0 & $2.7^{*}$ \\
\hline $\begin{array}{l}\text { Use indenting, blank lines, etc., to } \\
\text { make listings easy to read }\end{array}$ & 4.3 & $3.8^{*}$ \\
\hline
\end{tabular}

Note-Ratings were on a scale of 1 (do not believe in or never do) to 5 (believe in or always do). $\quad * p<.01$.

still consume substantial time and effort from those individuals who use the languages.

With a couple of exceptions, the language learned first by the respondents had little effect on their later language choices. Programmers whose first language was BASIC reported significantly more current use of BASIC than did those who had learned any other language first. No other language commanded the loyalty shown by users of BASIC; individuals who first learned FORTRAN, for example, did not report current use of FORTRAN to a greater extent than did those who learned, for example, with assembly languages. The only other relationship between first language and current use was in the use of BASIC by programmers who cut their teeth on assembly languages; they reported almost no current use of Apple BASIC, but otherwise did not differ from other respondents.

\section{Matching Languages and Applications}

A free-response section of the survey asked several questions about applications, specific features, and strengths and weaknesses of the respondent's two most often used languages. The languages that were cited by 3 or more respondents (BASIC, C, FORTRAN, LISP, Pascal, and various assemblers) were studied in more detail. Infrequently used languages, code for statistical packages (e.g., SAS or SPSS), scripts in operating system command languages, and macros for microcomputer packages (dBase, Excel, etc.) were excluded from further analysis. As Table 7 shows, the majority (70 out of 153 , or $46 \%$ ) of the reported applications were for lab control (including equipment control and data recording). Of those 70 applications, 33 (47\%) were coded in BASIC and $16(23 \%)$ in Pascal, and $10 \%$ of the lab applications were coded in assembler. On the other hand, nearly all of the assembler code ( 7 out of 9 , or $78 \%$ ) was for lab control. The final column in Table 7 shows the applications as a percentage of code written, rather than as a percentage of all applications reported. The two columns mirror each other, except in the case of lab control and language processing applications. In the former, $36 \%$ of the code written was devoted to lab use, whereas more of the programs themselves $(45 \%)$ were for the lab. Although very few reported applications were for language processing $(2.6 \%)$, such applications are more lengthy, occupying $10.8 \%$ of the code written.

Statistical applications were coded primarily in FORTRAN (31\%) or BASIC (42\%), with Pascal (19\%) as third choice. For simulation, the respondents showed a diversity of language choice; $36 \%$ of the simulations were written in BASIC, with several coded in FORTRAN, LISP, and Pascal. Data handling applications, which tended to be of the "quick and dirty" variety, were coded in the language of convenience, primarily BASIC, FORTRAN, and Pascal. LISP was preferred for text processing and for the single reported AI program.

Table 8 summarizes the reasons why individuals chose to write their projects in particular languages. Only 17 $(10 \%)$ of the 168 responses could be interpreted as meaning that the language chosen was particularly well suited to the task. The majority of the respondents chose a language because it was easy to use on the equipment that they had available (24\%), or was dictated in some way by hardware ("only choice available," "allows PEEK/POKE hardware access," or similar reasons) (21\%). Among other reasons for language choice were familiarity (14\%) and portability (14\%). FORTRAN was very likely to be chosen for reasons of familiarity ("in- 
Table 6

Use of Languages

\begin{tabular}{lccc}
\hline Language & $\begin{array}{c}\text { Mean Percent } \\
\text { of All Code }\end{array}$ & $\begin{array}{c}\text { Respondents } \\
\text { Reporting Use }\end{array}$ & $\begin{array}{c}\text { Mean Percent of } \\
\text { Respondents' Code }\end{array}$ \\
\hline Applesoft BASIC & 15.0 & 36 & 51.6 \\
All other BASICs & 24.3 & 54 & 54.4 \\
FORTRAN (IV and 77) & 8.8 & 40 & 27.2 \\
Pascal & 18.5 & 41 & 52.4 \\
C & 9.3 & 24 & 44.2 \\
LISP & 6.1 & 22 & 31.2 \\
FORTH & 1.8 & 4 & 50.0 \\
Apple II assembly & 1.4 & 8 & 19.5 \\
IBM PC (or clone) assembly & 1.1 & 9 & 13.6 \\
All other assemblers & 1.6 & 12 & 14.2 \\
Modula & 1.0 & 2 & 55.0 \\
All other languages* & 15.0 & 38 & 42.3 \\
\hline
\end{tabular}

Note- $N=135$. $\quad$ Includes SAS, macros for personal computer programs, etc.

Table 7

Applications by Language

\begin{tabular}{|c|c|c|c|c|c|c|c|c|c|}
\hline & \multicolumn{6}{|c|}{ Number of Applications Reported } & \multirow{2}{*}{$\begin{array}{c}\text { Total } \\
\text { Programs }\end{array}$} & \multirow{2}{*}{$\begin{array}{c}\text { Percent } \\
\text { of all } \\
\text { Programs }\end{array}$} & \multirow{2}{*}{$\begin{array}{c}\text { Percent } \\
\text { of all } \\
\text { Code }\end{array}$} \\
\hline & Assembly & BASIC & C & FORTRAN & LISP & Pascal & & & \\
\hline AI & - & - & - & - & 1 & - & 1 & 0.6 & 1.0 \\
\hline Data handling & 1 & 9 & 1 & 3 & - & 5 & 19 & 12.4 & 12.4 \\
\hline Instructional & - & 7 & - & - & 2 & 2 & 11 & 7.1 & 4.0 \\
\hline Lab control & 7 & 33 & 10 & 4 & - & 16 & 70 & 45.0 & 36.4 \\
\hline Simulation & - & 8 & 2 & 4 & 4 & 4 & 22 & 14.3 & 16.0 \\
\hline Statistics & - & 11 & 2 & 8 & - & 5 & 26 & 16.9 & 19.2 \\
\hline Text/language & 1 & - & - & - & 2 & 1 & 4 & 2.6 & 10.8 \\
\hline Total & 9 & 68 & 15 & 19 & 9 & 33 & 153 & & \\
\hline
\end{tabular}

Table 8

Reasons for Choosing a Language

\begin{tabular}{lccrcccc}
\hline & Assembly & BASIC & C & FORTRAN & LISP & Pascal & Total \\
\hline Capable for task & - & 7 & 3 & 3 & - & 4 & 17 \\
Easy to use on & - & 24 & - & 3 & - & 13 & 40 \\
$\quad$ equipment & & & & & & & \\
Equipment dictated & 3 & 26 & 3 & 1 & - & 3 & 36 \\
Familiar & - & 12 & 2 & 10 & - & - & 24 \\
Libraries available & - & 3 & - & 4 & - & 2 & 9 \\
Portable & - & 12 & 4 & - & - & 7 & 23 \\
Speed & - & 5 & - & 5 & 3 & - & 13 \\
"Standard" & - & - & 3 & - & 3 & - & 6 \\
Total & 3 & 89 & 15 & 26 & 6 & 29 & 168 \\
\hline
\end{tabular}

ertia" or "tradition," as 2 respondents admitted). Portability was especially important to Pascal and C users, and the capabilities of FORTRAN were important for numeric applications. BASIC constituted $72 \%$ of the equipment-dictated choices, a testimony to its widespread use in labs. Most of these BASIC users commented that they needed the hardware access that BASIC provided on a particular machine, suggesting that, for them at least, BASIC really was the most capable language for the task.

LISP and C were cited as being in some sense "standard" for their tasks. LISP (and close relatives) were chosen as the "standard" language for AI applications, and $C$ was the chosen language in several labs where the UNIX standard prevails. Libraries of prewritten code were particularly important to FORTRAN users, but
BASIC and Pascal programmers also commented that libraries were important factors in their language choices.

Choice of language was not influenced by formal training in computer science. There were no significant differences in the mean percents of code written in the various languages as a function of whether the programmers had training in computer science.

The results of the survey indicate that psychologists tend to choose languages that are familiar and easy to use, but that they are also alert to the special features of the languages. There was no reported instance of a data handling, lab control, or statistics program coded in LISP, for example; LISP is reserved for simulation and text handling. For computationally intensive applications, respondents reported using the numeric capabilities of FOR- 
Table 9

Strengths by Language

\begin{tabular}{|c|c|c|c|c|c|c|c|}
\hline & Assembly & BASIC & $\mathrm{C}$ & FORTRAN & LISP & Pascal & Total \\
\hline Easily available & - & 9 & - & $\rightarrow$ & - & - & 9 \\
\hline $\begin{array}{l}\text { Easy to debug/ } \\
\text { maintain }\end{array}$ & - & 5 & - & $\cdots$ & - & - & 5 \\
\hline Easy to leam/code & - & 38 & - & - & - & - & 38 \\
\hline Flexible & - & 3 & 5 & 一 & 1 & - & 9 \\
\hline I/O facilities & - & - & - & 2 & - & - & 2 \\
\hline Nonnumeric ability & - & - & - & - & 3 & 1 & 4 \\
\hline Numeric ability & - & - & - & 5 & - & - & 5 \\
\hline Portable & - & 10 & 3 & 6 & - & - & 19 \\
\hline Readable code & - & 1 & 2 & - & - & 7 & 10 \\
\hline Recursive & - & - & - & - & 1 & - & 1 \\
\hline Speed of execution & 4 & - & 2 & - & - & 6 & 12 \\
\hline Structured & - & - & 7 & - & 1 & 19 & 27 \\
\hline $\begin{array}{l}\text { Subroutines and } \\
\text { libraries available }\end{array}$ & - & 2 & 1 & 1 & - & 1 & 5 \\
\hline Variable typing & - & - & - & - & - & 2 & 2 \\
\hline No strengths & 1 & - & - & 1 & - & - & 2 \\
\hline Total & 5 & 68 & 20 & 15 & 6 & 36 & 150 \\
\hline
\end{tabular}

Table 10

Weaknesses by Language

\begin{tabular}{|c|c|c|c|c|c|c|c|}
\hline & Assembly & BASIC & $\mathrm{C}$ & FORTRAN & LISP & Pascal & Total \\
\hline $\begin{array}{l}\text { Cumbersome to } \\
\text { code or use }\end{array}$ & - & 14 & - & 1 & - & - & 15 \\
\hline $\begin{array}{l}\text { Data structures } \\
\text { (or lack of) }\end{array}$ & - & - & - & 3 & - & - & 3 \\
\hline Hard to learn/code & 3 & - & 5 & - & 1 & - & 9 \\
\hline $\begin{array}{l}\text { Limited } \mathrm{I} / \mathrm{O} \text { and } \\
\text { file capability }\end{array}$ & - & 5 & 1 & 1 & - & 4 & 11 \\
\hline $\begin{array}{l}\text { Nonnumeric } \\
\text { (in)ability }\end{array}$ & - & - & - & 3 & - & 1 & 4 \\
\hline Not portable & 2 & - & - & - & - & - & 2 \\
\hline Slow execution & - & 11 & - & - & - & 3 & 14 \\
\hline Structure (lack of) & - & 14 & - & 4 & - & - & 18 \\
\hline $\begin{array}{l}\text { Subroutines and } \\
\text { libraries not } \\
\text { available }\end{array}$ & - & 4 & - & - & 1 & 17 & 22 \\
\hline $\begin{array}{l}\text { Syntax and/or } \\
\text { rules }\end{array}$ & - & 1 & 3 & 1 & 1 & 2 & 8 \\
\hline $\begin{array}{l}\text { Variable typing } \\
\text { and/or names }\end{array}$ & 一 & 7 & - & 2 & - & 3 & 12 \\
\hline No weaknesses & - & - & 2 & 2 & 3 & - & 7 \\
\hline Total & 5 & 56 & 11 & 17 & 6 & 30 & 125 \\
\hline
\end{tabular}

TRAN and Pascal. (The 2 respondents who reported using APL for these applications did so specifically for that language's matrix abilities.) The ubiquitous BASIC was applied to nearly every task reported by the respondents except for $\mathrm{AI}$ and text processing. It was clear, though, that respondents did not generally define the specifications for a project and then select the language best suited for it; the choices were too often dictated by convenience and/or familiarity, even at the expense of extra work.

\section{Language Strengths and Weaknesses}

The respondents were asked to identify strengths and weaknesses of their primary languages (see Tables 9 and 10). Some wrote impassioned comments about various features and/or implementations. Some respondents cited weaknesses or strengths of particular implementations of languages-for example, they liked (or hated) the develop- ment environment, they could (or could not) get access to particular machine locations, the language was only compiled (or only interpreted). As much as possible, the tables reflect the features of the languages and not the implementations, although in some cases the comments could not be attributed clearly to one or the other.

BASIC's main strength, apart from its wide availability and ease of use, seemed to be that it is easy to learn and code in. Of all of the languages, the phrases "easy to learn" or "easy to write in" were applied only to BASIC. Its wide availability and portability were cited as strengths by some programmers. But although it may be easy to learn and use, a substantial number of respondents described BASIC as "cumbersome" (some of these comments might have been implementation specific). BASIC was faulted by a number of respondents for being slow (at least in interpreted implementations), hav- 
ing poor variable typing/parameter passing/naming rules, and having no structuring facilities. The latter weakness was often cited in conjunction with complaints about parameter passing, local/global variables, or difficulties in establishing and/or linking to subroutine libraries. Several respondents noted that TrueBASIC and some other dialects allow "as much structuring as you want."

C's few users rated it as flexible, highly portable, readable, and fast, although they admit that it is hard to learn, with a difficult syntax and complex rules. Two C programmers reported no weaknesses in the language.

FORTRAN's most notable strengths appear to be its portability and its numeric ability, though a few users mentioned its flexible $\mathrm{I} / \mathrm{O}$ as a strength as well. FORTRAN was faulted for its lack of data structures (which was not even mentioned as an equally applicable fault for BASIC) and control structures. Several respondents found FORTRAN's difficulty in dealing with nonnumeric data to be a weakness.

LISP was used even less often than $\mathrm{C}$ by the respondents, and its most often cited strength was its ability with nonnumeric data (indeed, this was usually why it was chosen). Flexibility and the ability to handle recursive functions were its other strengths. (It is interesting to note that recursion was mentioned only in connection with LISP; since other languages are also recursive, this suggests that perhaps psychologists do not value or use recursion.)

Since program structure is highly valued in computer science courses, and since Pascal is structured and is taught in such courses, it comes as no surprise that structure was the most frequent advantage cited for Pascal. The next most frequent advantage also comes as no surprise: Pascal produces readable code (this was also cited as an advantage for BASIC, C, and FORTRAN by at least 1 person each). Several respondents cited speed as an important strength of Pascal, but nearly all of these comments referred to specific implementations; Pascal's slowness was mentioned by others. Pascal was also faulted for making $\mathrm{I} / \mathrm{O}$ and file use difficult; for having difficulty in finding, linking, compiling, and using subroutine libraries; and for having a difficult syntax.

\section{Reference and Text Materials}

Respondents were asked to list reference or learning materials for the languages that they used most. For nearly all languages, the most frequent, or (often unhappily) the only, source was the manual supplied by the computer or language vendor. A number of people listed materials that they found helpful; these recommendations are listed in the Appendix.

\section{DISCUSSION}

The psychologist programmers surveyed are apparently familiar with the rules of structured programming com- ing from the discipline of computer science, but their actual use of these principles is significantly lower than the value they place on them. Psychologists could improve their programming with a little more attention to some of the recommendations. There are reasons for limiting modules to one page and for indenting. Indenting tends to make programs more comprehensible, whereas short modules are not only more understandable, but they also encourage program development and testing in small segments. There is a reason for avoiding GOTOs (even when the language allows them), for avoiding jumps into and out of loops, and for having neat modules with single entry and exit points. Following these rules makes listings easy to read and avoids the tangled webs of program flow often called "spaghetti code." There is a reason for topdown design: It leads to clearer, more systematic, and probably more efficient program development. There is a reason for comments and documentation (we need not belabor this point). These suggestions on coding style apply equally to BASIC or FORTRAN programmers and to "structured language" programmers.

The respondents admit to following guidelines for good programming less than they should. But as an occasional reviewer of some of their code, I have a suspicion that the respondents actually overestimated the degree to which they follow the recommendations. If they actually do follow the guidelines to the extent that their answers suggest, then there must be more really good, clean, readable code out there than I encounter.

The psychologists surveyed are a practical lot. They use a computer to solve a problem, and tend to program in whatever language and on whatever machine they find most convenient. Their choice of language is often dictated by equipment demands first and characteristics of programming languages second. The overwhelming use of BASIC as a laboratory control language speaks not to the features of the language but rather to its early and close association with the Apple II as a lab machine.

Given nearly equal capability of two languages to solve a problem, the psychologists surveyed let familiarity decide the language. Although some respondents are clearly multilingual, there is little evidence to suggest that they choose a programming language primarily by seeking a match between an application's requirements and a language's strengths. With few exceptions (mainly in AI, text processing, and, to some extent, number crunching), languages are selected because, as is the case with BASIC and Pascal, they are known and available and can be made to do the job.

But perhaps our language choices are made just as they should be-we are not computer professionals, but pragmatic psychologists trying to do a job. Although we may recognize that there are languages that will fit some of our tasks better than those we already know, learning a new language can be a major investment of time and effort, one that can only detract from our professional work. 


\section{APPENDIX}

Suggested Reference and Text Materials (Still in Print)

\section{Assembly}

DEJong, M. L. (1982). Apple II assembly language. Indianapolis: Sams. BASIC

CoAN, J. S. (1983). Basic Apple BASIC. Hasbrouck Heights, NJ: Hayden.

CulP, G., \& NickLes, H. (1983). An Apple for the teacher. Belmont, CA: Wadsworth. Any Beagle Brothers material.

\section{C}

Harbison, S. S., \& Steele, G. L. (1984). C: A reference manual. Englewood Cliffs, NJ: Prentice-Hall.

KernighaN, B., \& Ritchie, P. M. (1978). The $C$ programming language. Englewood Cliffs, NJ: Prentice-Hall.

Kochan, S. G. (1984). Programming in C. Hasbrouck Heights, NJ: Hayden.

\section{FORTH}

Brodie, L. (1984). Starting FORTH. Encinitas, CA: Micro Works. BRODIE, L. (1984). Thinking FORTH: A language and philosophy for solving problems. Englewood Cliffs, NJ: Prentice-Hall.

\section{FORTRAN}

Friedman, F. L., \& Kofrman, E. B. (1981). Problem solving and structured programming in FORTRAN (2nd ed.). Reading, MA: AddisonWesley.

LeHMAN, R. S. (1977). Computer simulation and modeling. Hillsdale, NJ: Erlbaum.

LeHMAN, R. S. (1986). Programming for the social sciences. Hillsdale, NJ: Erlbaum.

MCCRACKEN, D. (1974). A simplified guide to FORTRAN programming . New York: Wiley.

\section{LISP}

TOURETSKY, D. (1984). LISP. New York: Harper \& Row. WiLENSKY, R. (1984). LISPCrafi. New York: Norton.

\section{Pascal}

Cooper, D., \& Clancy, M. (1982). Oh! Pascal! New York: Norton. Grogano, P. (1980). Programming in Pascal. Reading, MA: AddisonWesley.

SANDs, P. A. (1984). Advanced Pascal programming techniques. New York: McGraw-Hill. 